29 Swenne I, Crace CJ, Milner RDG. Persistent impairment of insulin secretory response to glucose in adult rats after limited period of protein-calor malnutrition early in life. Diabetes $1987 ; 36: 454-8$

30 Gopalan C, Venkatachalam PS, Rao KS, Menon PS. Studies on nutritional edema: clinical, biochemical and pathological observations. Indian $7 \mathrm{Med}$ Sci 1952;6:277-95.

31 Smith SR, Edgar PJ, Pozefsky T, Chetri MK, Prout TE. Insulin secretion and glucose tolerance in adults with protein-calorie malnutrition. Metabolism 1975;24:1073-84

32 Cook GC. Glucose tolerance after kwashiorkor. Nature 1967;215:1295-6.

33 Becker DJ, Pimstone BL Hansen JDL Hendricks S. Insulin secretion in protein-calorie malnutrition. 1. Quantitative abnormalities and response to Preatment. Diabutes 1971;20:542-51.

34 Snoeck A, Remacle C, Reusens B, Hoet JJ. Effect of a low protein die: during pregnancy on the fetal rat endocrine pancreas. Biol Neonate 1990;57:107-18.

35 Hales CN, Barker DJP, Clark PMS, Cox LJ, Fall C, Osmond C, et al. Fetal and infant growth and impaired glucose tolerance at age 64. BMF 1991;303:1019-22

36 Bennett PH, Bogardus C, Tuomilehto J, Zimmet P. Epidemiology and natural history of NIDDM: non-obese and obese. In: Alberti KGMM, DeFronzo $\mathrm{RA}$, Keen $\mathrm{H}$, Zimmet $\mathrm{P}$, eds. International textbook of diabetes mellitus. Chichester: John Wiley and Sons, 1992:147-76.

37 Davies JNP. The essential pathology of kwashiorkor. Lancet 1948;i:317-20.

38 Nwokolo C, Oli J. Pathogenesis of juvenile tropical pancreatitis syndrome. Lance 1980;i:457-9.
39 Shaper AG. Chronic pancreatic disease and protein malnutrition. Lance 1960;i:1223-4.

40 Olurin EO, Olurin O. Pancreatic calcification: a report of 45 cases. BMJ 1969;iv:534-9

41 Lester FT. A search for malnutrition diabetes in an Ethiopian diabetic clinic. International Diabetes Foundation Bulletin 1984;29:14-6.

42 McLarty D, Pollitt C, Swai ABM. Diabetes in Africa. Diabetic Med 1990;? 670-84

43 Tanner JM, Healy MJR, Lockhart RD, MacKenzie JD. Whitehouse RH. Aberdeen growth study. 1. The prediction of adult body measurements from measurements taken each year from birth to 5 years. Arch Dis Child 1956;31:372-81.

44 Whincup PH, Cook DG, Shaper AG. Social class and height. BMF 1988;197

45 Walker M, Shaper AG, Wannamethee G. Height and social class in middleaged British men. F Epidemiol Commumity Health 1988;42:299-303.

46 Pitchumoni CS, Jain NK, Lowenfels AB, DiMagno EP. Chronic cyanide poisoning: unifying concept for alcoholic and tropical pancreatitis. Pancreas 1988;3:220-2

47 Swai ABM, McLarty DG, Mtinangi BKL, Tatala S, Kitange HM, Mlingi N, et al. Diabetes is not caused by cassava toxicity: a study in a. Tanzania community. Diabetes Care (in press).

(Accepted 8 Siptember 1992)

\title{
Decision to treat mild hypertension after assessment by ambulatory monitoring and World Health Organisation recommendations
}

\author{
Gilles Chatellier, Christiane Battaglia, Jean-Yves Pagny, Pierre-François Plouin, Joël Ménard
}

\begin{abstract}
Abstrtact
Objective-To determine if one ambulatory blood pressure recording over 12 hours could detect those patients with mild hypertension who needed treatment according to the World Health OrganisationInternational Society of Hypertension (ISH) guidelines based on the casual measurement of diastolic blood pressure at successive visits to a clinic.

Design-Comparison of decision to treat based on one ambulatory measurement over 12 hours and standard blood pressure measurements over six months in the same patients.

Setting-Outpatient hypertension clinic.

Subjects-130 men and women with diastolic blood pressure of $90-104 \mathrm{~mm} \mathrm{Hg}$ at second visit to clinic.

Main outcome measures-Blood pressure measurements over six months. Measurement from ambulatory monitoring. Decision to treat.

Results-Of the 130 patients included, 108 were followed up over the six months. Treatment was started according to WHO-ISH criteria in 44 (13 at the third visit, 13 at the fourth, 18 at the fifth). According to the selected criteria for ambulatory blood pressure monitoring 41 patients would have been treated. Both methods agreed that the same 27 patients required treatment and the same 50 did not, but they did not agree in 31 patients. When calculated at the optimal diastolic blood pressure threshold determined by a receiver operating characteristic curve, the sensitivity, specificity, and positive predictive value of ambulatory blood pressure monitoring were $71 \% \quad(95 \%$ confidence interval $57 \%$ to $84 \%), 82 \%(72 \%$ to $92 \%)$, and $66 \%$ $(51 \%$ to $81 \%)$, respectively.
\end{abstract}

Conclusion-If the WHO-ISH criteria are accepted as the standard for deciding to treat patients with mild hypertension the predictive value of one ambulatory blood pressure recording over 12 hours is too low to detect with confidence those patients who need treatment when managed according to these criteria.

\section{Introduction}

In patients with mild hypertension the decision to treat is an important issue that has again come to the fore with the availability of several new techniques for measuring blood pressure. The rise in blood pressure induced by the act of measurement itself, referred to as the "white coat reaction," may lead to a false diagnosis of hypertension.' This is one reason why $40 \%$ of the patients included in large scale hypertension trials subsequently became normotensive with placebo. ${ }^{23}$

The guidelines from the World Health OrganisationInternational Society of Hypertension (ISH) take this into account and recommend multiple mesurements over six months before treatment is started. ${ }^{+}$The basis for such a policy is, firstly, that multiple measurements may be expected to give a closer estimation of the true blood pressure and, secondly, that repetition of measures over time may decrease the reaction induced by the visit to the doctor. This protocol is presently the gold standard for the decision to treat mild hypertension because epidemiological data, classification of hypertension, and evaluation of treatment efficacy are all based on clinic readings and because the white coat reaction has been shown to diminish considerably after four months. ${ }^{2}$ This protocol, however, is tedious, risks losing patients to follow up, and the extent of its correct use by general practitioners is unknown. Consequently, it may prove to be less useful than expected when applied in reality.

Ambulatory blood pressure monitoring is a widely accepted method of measuring blood pressure, which avoids the white coat reaction' and becomes increasingly acceptable to patients as the equipment gets smaller. The value of a single ambulatory record in predicting the need for treatment has never been compared with that of a reference method. We assessed the predictive value of one 12 hour ambulatory blood pressure record for the decision to treat patients with mild hypertension by comparing it with the decision made during the six months' follow up in the clinic, according to the WHO-ISH protocol. ${ }^{+}$

\section{Patients and methods}

A total of 154 men and women who were referred to the hypertension clinic of the Broussais University Hospital for evaluation of their hypertension were screened for inclusion in the present study. The inclusion criteria were (a) casual diastolic blood 
pressure between 90 and $110 \mathrm{~mm} \mathrm{Hg}$; $(b)$ absence of symptomatic cardiovascular disease; (c) absence of secondary hypertension; and (d) willingness to participate in the study. Patients already taking drugs for hypertension were not necessarily excluded. Those patients in whom the indication for pharmaceutical treatment was questionable were considered for the inclusion after at least a 15 day wash out period.

\section{STUDY PROTOCOI}

Each patient fulfilling the inclusion criteria was referred at least two weeks after the screening visit to the physician in charge of the study. Patients were included if their casual blood pressure without treatment remained in the $90-104 \mathrm{~mm} \mathrm{Hg}$ range at this consultation. The 12 hour ambulatory recording was performed after this visit with the Spacelabs 5200 monitor. Each patient then attended four additional visits at the outpatient clinic over six months. The ambulatory monitoring results were not made available to the physician in charge of the patients until the end of the study. The decision to treat was based on diastolic blood pressure figures obtained at the clinic according to the WHO-ISH guidelines (diastolic blood pressure $>100 \mathrm{~mm} \mathrm{Hg}$ at the third and fourth visit and $>95 \mathrm{~mm} \mathrm{Hg}$ at the fifth visit).

The decision made by the physician was then compared retrospectively with the decision that would have been from the ambulatory recording alone. Patients were arbitrarily classified as requiring treatment if their mean diastolic blood pressure was 2 SD above age specific values obtained previously with the same device in 130 normotensive volunteers. The critical limit was $88 \mathrm{~mm} \mathrm{Hg}$ in the age range 18-29 years, $91 \mathrm{~mm} \mathrm{Hg}$ in the age range 30-39, and $94 \mathrm{~mm} \mathrm{Hg}$ at 40 or over.

\section{MANUAL BLOOD PRESSURE MEASUREMENT}

The same physician was in charge of all the patients throughout the study, and she performed all the clinical blood pressure measurements. At each visit a single blood pressure measurement was performed in the morning with a mercury sphygmomanometer. The same arm was used for the same patient after 15 minutes in the lying position. Phase $\mathrm{V}$ of the Korotkoff sounds was taken as the diastolic blood pressure. As no patient had a large arm circumference the same standard cuff $(12 \times 22 \mathrm{~cm})$ was used for all patients.

\section{AMBUI ATORY BI.OOD PRESSLRE MEASLREMENT}

Ambulatory blood pressure was monitored with the Spacelabs 5200 monitor. The cuff (standard adult size, $12 \mathrm{~cm}$ width) was applied to the non-dominant arm. The device was programmed to measure blood pressure every 20 minutes from 8 am to 8 pm during a day of typical activity for each subject. The patients were told to cease activity and keep their arm still during each measurement. The monitor uses either a microphone or an oscillometer to detect systolic and diastolic blood pressure. The oscillator intervenes when the microphone fails to identify a recognisable Korotkoff signal.

We have previously shown that the Spacelabs monitor 5200 gives a mean (SD) diastolic blood pressure 5.3 (6) $\mathrm{mm} \mathrm{Hg}$ lower than the mean diastolic blood pressure measured simultaneously with a Remler M2000 monitor." In this study the Spacelabs monitor was compared with the auscultation method according to the following procedure. After the initial manual blood pressure measurement (and after five minutes' rest) the Spacelabs monitor was applied to the nondominant arm and two successive measurements performed while the physician simultaneously measured the blood pressure on the opposite arm with

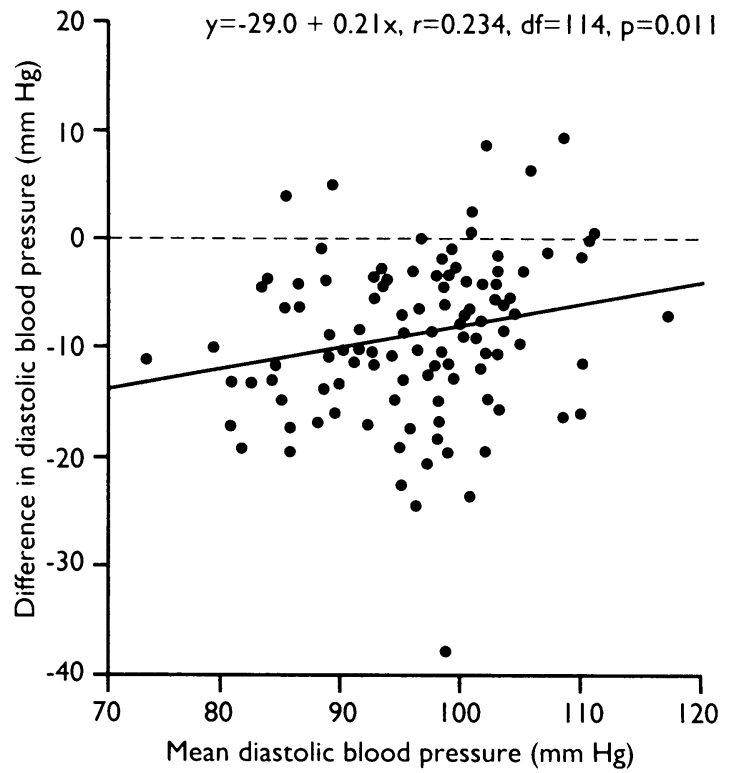

FIG 1--Comparison of blood pressure recorded simultaneously by physician and by Spacelabs 5200 monitor according to method of Bland and Altman.' Mean diastolic blood pressure was obtained by averaging pressure measured by physician and by device, and difference was calculated as pressure measured by device minus pressure measured by physician. Data were missing on three patients

a mercury sphygmomanometer. Each set of two measurements was averaged and the mean of the two methods was plotted against their difference according to the method of Bland and Altman (fig 1). The monitor gave a diastolic blood pressure value 8.4 $(7 \cdot 2) \mathrm{mm} \mathrm{Hg}$ lower (range 10 to $-37 \mathrm{~mm} \mathrm{Hg}$ ) than that of the physician. The magnitude of the difference depended on the blood pressure level $(r=0 \cdot 234$, $\mathrm{df}=114, \mathrm{p}=0.011)$ and tended to decrease with increasing blood pressure.

DATA ANALYSIS

The Spacelabs computer eliminated obvious technical inconsistencies and artefactual readings. We also eliminated blood pressure readings when the difference between the systolic and diastolic blood pressure was less than $20 \mathrm{~mm} \mathrm{Hg}$ and the systolic blood pressure was $>160 \mathrm{~mm} \mathrm{Hg}$ and when the difference between systolic and diastolic blood pressure was $>140 \mathrm{~mm} \mathrm{Hg}$. The two ambulatory readings obtained during the comparison of the two methods were not included in the 12 hour analysis. The remaining values were averaged for each patient, and the mean (SD) number of readings per patient was 35 (5), (range 17-44). This range was large because some patients did not undergo the full 12 hours of recording, and the device was sometimes unable to obtain measurements and therefore recorded an error code.

Data are shown as means (SD). Comparison of two means was performed with an unpaired Student's $t$ test. One way analysis of variance was used to compare multiple means $(>2)$. The relation between two variables was analysed with Pearson's correlation coefficient. Concordance between the two diagnostic methods was studied with the kappa coefficient." A receiver operating characteristic curve (ROC curve) was obtained by plotting the sensitivity (y axis) against 1 -specificity ( $x$ axis) of the ambulatory method for different cut off points." A p value less than 0.05 was considered significant.

\section{Results}

The course of the study is shown in figure 2. Of the 154 patients screened for the study, 35 were not included at the first visit (19 because their diastolic blood pressure was $<90 \mathrm{~mm} \mathrm{Hg}$ and 15 because it was 


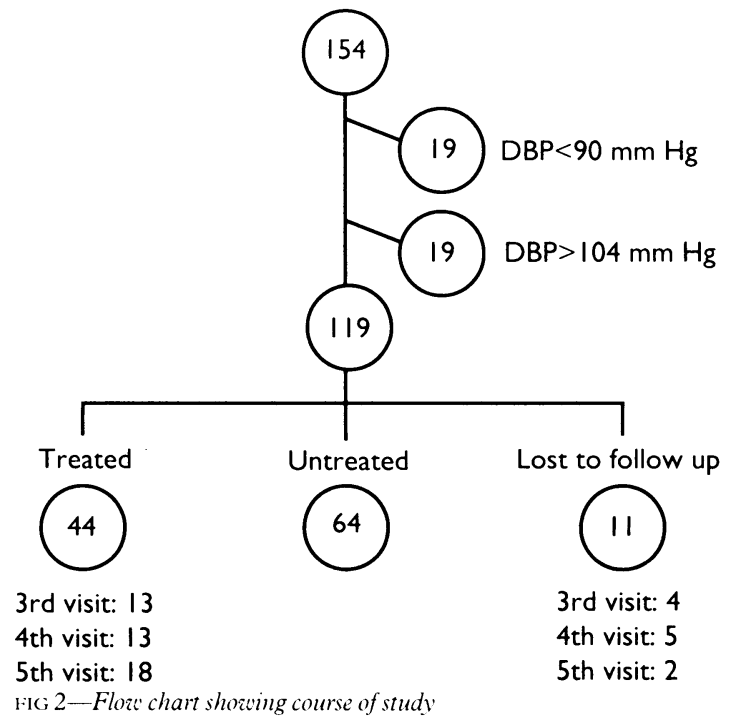

$>104 \mathrm{~mm} \mathrm{Hg}$ ). The remaining 119 patients ( 84 men, 35 women) had a mean (SD) age of $41.9(13.0)$ years and a mean (SD) blood pressure of $152 \cdot 1(16 \cdot 5) / 96 \cdot 4$ $(4 \cdot 4) \mathrm{mm} \mathrm{Hg}$. Thirty three $(27 \cdot 7 \%)$ were taking drugs for hypertension. Eleven patients were lost to follow up, leaving 108 patients for the final analysis. Patients lost to follow up had a lower age $(34.8$ (18) $v 42.6$ (12) years) and a higher body mass index (weight $\left.(\mathrm{kg}) /(\text { height }(\mathrm{m}))^{2}: 26(4) v 24(3) \mathrm{kg} / \mathrm{m}^{2}\right)$ than the other patients, whereas the percentage of men $(72.7 \%$ and $70.4 \%$ respectively) and blood pressure levels (157 (23)/97 (5) v $152(16) / 96(4))$ were comparable in the two groups.

At the end of the six month follow up 44 of the 108 patients $(40.7 \%)$ were prescribed antihypertensive drugs on the basis of the WHO-ISH recommendations. Treatment was initiated at the third consultation in 13 patients, at the fourth consultation in 13 , and at the fifth consultation in 18 patients. With the selected treatment threshold for ambulatory blood pressure 41 patients $(40 \cdot 0 \%)$ were classified retrospectively as requiring treatment. This proportion was not

TABLE I-Comparison of physician's decision to treat mild hypertension (reference method) with that based on results of ambulatory monitoring

\begin{tabular}{lcccr}
\hline & \multicolumn{3}{c}{ Physician's decision to treat } & \\
\cline { 2 - 3 } & Yes & No & Total \\
\hline Ambulatory blood pressure: & & & \\
Above treatment threshold & 27 & 14 & 41 \\
Below treatment threshold & 17 & 50 & 67 \\
\hline Total & 44 & 64 & 108
\end{tabular}

Sensitivity: $61 \cdot 4 \%(95 \%$ confidence interval $47 \cdot 0 \%$ to $75 \cdot 8 \%)$; specificity: $78 \cdot 1 \%(68 \cdot 0 \%$ to $88 \cdot 2 \%)$; positive predictive value: $65.9 \%(51 \cdot 4 \%$ to $80 \cdot 4 \%$

* Treatment threshold retrospectively defined in each patient by mean ambulatory diastolic pressure 2 SD above age specific values.

TABLE II-Comparison of characteristics of three groups of patients whose blood pressure was measured by standard methods and ambulatory monitoring. Figures are means $(S D)$ unless stated otherwise

\begin{tabular}{|c|c|c|c|c|}
\hline & $\begin{array}{l}\text { Treatment not indicated } \\
\text { by either method }\end{array}$ & $\begin{array}{c}\text { Discordance } \\
\text { between methods }\end{array}$ & $\begin{array}{l}\text { Treatment indicated } \\
\text { by both methods }\end{array}$ & $\begin{array}{l}\text { p Value } \\
\left(F \text { or } \chi^{2}\right)\end{array}$ \\
\hline No of patients & 50 & 31 & 27 & \\
\hline Age (years) & $41 \cdot 3(13 \cdot 8)$ & $42 \cdot 0(10 \cdot 5)$ & $45 \cdot 5(11 \cdot 1)$ & 0.34 \\
\hline No $(\%)$ men & $35(70 \cdot 0)$ & $20(64 \cdot 5)$ & $20(74 \cdot 1)$ & 0.73 \\
\hline No $(\%)$ previously treated & $14(27 \cdot 0)$ & $10(32 \cdot 3)$ & $8(29 \cdot 6)$ & 0.95 \\
\hline Body mass index $\left(\mathrm{kg} / \mathrm{m}^{3}\right)$ & $24 \cdot 5(2 \cdot 9)$ & $24 \cdot 7(3 \cdot 0)$ & $24 \cdot 3(3 \cdot 3)$ & 0.91 \\
\hline \multicolumn{5}{|l|}{ Blood pressure $(\mathrm{mm} \mathrm{Hg})$ : } \\
\hline Initial casual diastolic & $95 \cdot 2(4 \cdot 5)$ & $98 \cdot 4(3.8)$ & $96 \cdot 2(4 \cdot 0)$ & 0.005 \\
\hline Decisional casual diastolic ${ }^{\star}$ & $84.9(6.4)$ & $95.6(8.0)$ & $104 \cdot 9(5 \cdot 7)$ & $<0.001$ \\
\hline Average ambulatory diastolic & $83 \cdot 6(7 \cdot 1)$ & $90 \cdot 2(8 \cdot 1)$ & $99 \cdot 3(5 \cdot 7)$ & $<0.001$ \\
\hline Initial casual systolic & $151 \cdot 1(14 \cdot 8)$ & $155 \cdot 3(17 \cdot 2)$ & $148 \cdot 5(15 \cdot 7)$ & 0.25 \\
\hline Decisional casual systolic ${ }^{\star}$ & $141.3(11.9)$ & $145 \cdot 6(15 \cdot 2)$ & $147 \cdot 8(14 \cdot 5)$ & $0 \cdot 11$ \\
\hline Average ambulatory systolic & $132 \cdot 0(8 \cdot 4)$ & $138.3(11 \cdot 7)$ & $139 \cdot 3(10 \cdot 5)$ & 0.003 \\
\hline
\end{tabular}

* Measurement on which physician decided to treat. In patients who were not receiving treatment at end of study, this is blood pressure recorded at last visit. statistically different from the proportion of patients actually treated. The agreement between the two decisional criteria is shown in table I. The $x$ value for these results was $0.40(95 \%$ confidence interval 0.21 to 0.59$)$. This value, although significantly different from zero $(z=4 \cdot 2, \mathrm{p}<0 \cdot 001)$, did not imply a sufficient agreement between the two methods to be informative at the individual level.

If we assume that the gold standard for treatment is the WHO-ISH protocol, the decision to treat based on ambulatory blood pressure monitoring will depend on the cut off point selected a priori. If a treatment threshold for ambulatory diastolic blood pressure of $85 \mathrm{~mm} \mathrm{Hg}$ had been chosen independent of age, 75 patients would have been treated, but only 38 of these were treated based on the WHO-ISH protocol. If the threshold had been $95 \mathrm{~mm} \mathrm{Hg}$ then 32 patients would have been treated, but only 23 were actually treated.

We further explored this point by calculating the sensitivity and specificity of treatment thresholds for ambulatory measurement ranging from 80 to $100 \mathrm{~mm} \mathrm{Hg}$, independent of patient age, and then drawing a receiver operating characteristic curve (fig 3). If the same decisional importance is given to the sensitivity and the specificity-that is, false positive and false negative are considered equivalent - then the best cut off point is the one for which the quantity of sensitivity + specificity -1 is highest. This point corresponded to a mean ambulatory diastolic blood pressure of $91 \mathrm{~mm} \mathrm{Hg}$. At this threshold the sensitivity and the specificity of the ambulatory recording, by comparison with the reference method, were 70.5 $(57.0$ to 84.0$)$ and $81.8(71.7$ to 91.9$)$ respectively, values comparable to those obtained with our arbitrary age dependent cut off points.

Table II compares the main characteristics of the patients for whom the two decisional criteria were concordant with those for whom divergent decisions would have been made. The divergences could not be explained by age, proportion of men, body mass index, and proportion treated at screening, which did not differ between the three groups.

The variability in blood pressure indicated by the standard error of the blood pressure values obtained during the ambulatory monitoring did not differ between the three groups (untreated 10.0 (3.6),

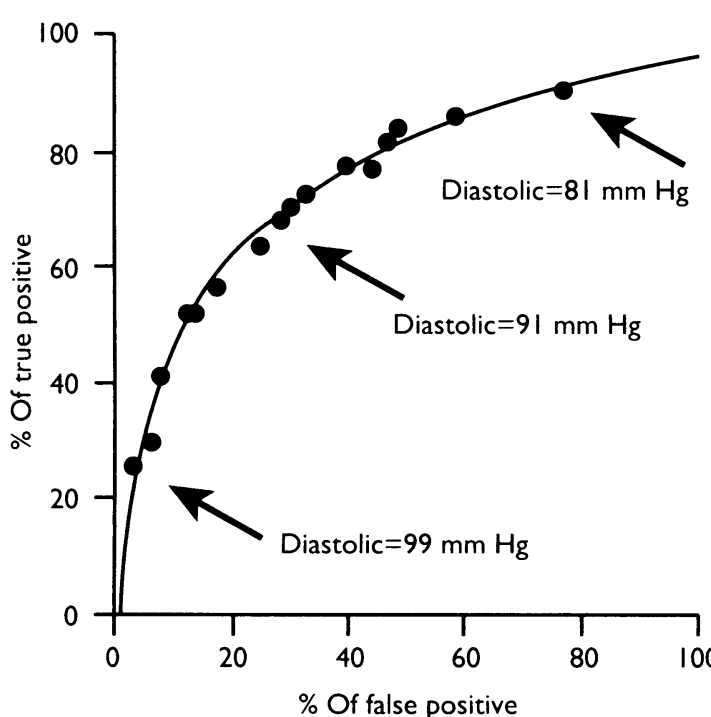

FIG 3-Receiver operating characteristic curve comparing percentage of true positive (sensitivity) and percentage of false positive (1-specificity) of ambulatory monitoring method for diagnosis of hypertension when WHO-ISH recommendations were considered as reference method. Each point of curve was obtained by calculating sensitivity and (1-specificity) at various ambulatory diastolic blood pressure values. Curve is obtained by fitting exponential curve with resulting equation: $y=0.97+0.52^{\star} \log (x) ; r^{\prime}=0.985$ 
discordant $10.5(3.0)$, treated $9.6(3.3) ; F=0.5$, $p=0 \cdot 60$ ). Measurement error, defined as the difference between the diastolic pressure measured by the physician (mean of two measures) and the diastolic pressure measured simultaneously by the automatic device on the opposite arm, differed significantly between the three groups (untreated 10.5 (6.8), discordant $7.9(6.0)$, treated $5 \cdot 1(6.6) ; F=5.41$, $\mathrm{p}=0.0056)$. This result, however, was explained by the negative correlation between this difference and the blood pressure level, as shown in figure 1.

Finally, the only significant difference between the three groups was in the blood pressure levels. The mean blood pressure was highest in the group of patients in whom both methods agreed that treatment should be started and lowest in the group in which both methods agreed that treatment should not be initiated. The blood pressure level of the group in which the methods were in disagreement was around the decisional thresholds for treatment.

\section{Discussion}

Our study shows that in a group of patients with mild hypertension the use of treatment criteria based on a single 12 hour ambulatory recording resulted in the same number of decisions to treat as the application of the WHO-ISH guidelines. ${ }^{+}$The correct application of these guidelines meant that only $44(40.7 \%)$ of the 108 patients referred to our clinic for advice were treated with drugs at the end of the six month follow up. Even if the recommendations provide a good means of selecting patients who need treatment, their feasibility in routine practice is questionable. Smith and Clayton recently showed large variations among British doctors in diagnosing hypertension, and only 24 of 187 patients labelled "hypertensive" had had three blood pressure readings before diagnosis." In addition, in many health care settings some patients may not accept a six month follow up period before a decision is made and could seek a second opinion.

An appropriate diagnosis of hypertension or an inappropriate decision to treat could lead to considerable overtreatment of normotensive or mildly hypertensive patients. By comparing ambulatory to casual measurement, Pickering et al found that white coat hypertension was present in $22 \%$ of 292 patients with mild hypertension defined by a diastolic blood pressure of 90-104 mm Hg. " A comparable figure was obtained by Weber and Drayer, who showed that $20 \%$ of subjects with levels $>140 / 90 \mathrm{~mm} \mathrm{Hg}$ according to repeated office readings were not hypertensive according to 24 hour ambulatory measurements. ${ }^{12}$ Using the Remler device, Waeber et al found that only $40 \%$ of 245 untreated patients considered by their physicians to be hypertensive had a mean blood pressure above $140 / 90 \mathrm{~mm} \mathrm{Hg}$ during the day.

About $60 \%$ of our patients remained untreated at the end of follow up, a percentage higher than in these previous studies. This result could be explained either by different patient selection or by the strict use of the WHO-ISH recommendations for the decision to treat, which resulted in longer follow up of patients and in a higher number of visits before initiation of treatment. Both repeated measurement and the passage of time are necessary to avoid overdiagnosis of hypertension. In the Australian trial, four months were necessary to avoid most of the overdiagnosis of hypertension.? Watson et al measured the blood pressure twice in standardised conditions on 12 occasions, about every week, in a group of 32 non-obese patients with hypertension. They found that a minimum of six sets of measurements were necessary before treatment was started. ${ }^{14}$ Thus, previous results and our present data suggest that a strategy based on six consultations over six months, although not validated by morbiditymortality studies, would avoid most of the overdiagnosis and overtreatment of hypertension.

The proportion of patients who would have been treated after a decision based on a single ambulatory record was comparable to that obtained by a physician following the WHO-ISH guidelines. Before proposing the replacement of casual measurements by this method, the potential benefits derived from the improved precision, reproducibility, and standardisation of the ambulatory measurement ${ }^{15}$ must be weighed against several difficulties. These include reliability, choice of the treatment threshold, and the health consequences of misclassifying patients.

We evaluated the reliability of the Spacelabs 5200 monitor in comparison with the Remler blood pressure recorder and found that the Spacelabs device underestimated the blood pressure. In this study the diastolic blood pressure measured by the Spacelabs monitor was $8.4 \mathrm{~mm} \mathrm{Hg}$ lower than that measured simultaneously by the physician. Casadei et al, however, found that the Spacelabs 5200 monitor overestimated the diastolic blood pressure by $2.9 \mathrm{~mm} \mathrm{Hg}$ when compared with the intra-arterial method. ${ }^{16}$ These discrepancies could be explained by errors in individual blood pressure readings or differences in the methods used (oscillometry versus Korotkoff sounds or direct measurement).

Although such discrepancies might be sufficient reason to discard these devices in routine practice, these limitations should be assessed in the context of the many reasons for the large interobserver differences seen with the auscultatory method. Aneroid manometers are still widely used by family practitioners, at least in France, despite their inaccuracy. Burke et al found that $30 \%$ of these devices had an error greater than $4 \mathrm{~mm} \mathrm{Hg}$ when compared to mercury sphygmomanometers and that $94 \%$ had a bladder shorter than the length recommended. ${ }^{17}$ Even if the device and the conditions of measurement are appropriate, observer bias is still a problem. In an epidemiological survey, regular and frequent retraining of technicians was necessary to decrease observer bias,,$^{18}$ a process which is not applied to general practitioners. Finally, there is an unavoidable random difference between two measurements performed on different occasions: the mean difference between indirect readings by the auscultatory method taken on two occasions for individual subjects was $7 \cdot 2 \mathrm{~mm} \mathrm{Hg}{ }^{19}$

Even if the measurement error or ambulatory blood pressure monitoring is acceptable, the choice of the reference level above which an ambulatory blood pressure can be defined as abnormal remains a major issue. The usual definition of an abnormal level is that above the upper limit of the normal range of values obtained in a strictly normotensive population, usually defined as being above the 90th percentile or the mean plus $2 \mathrm{SD}$. The diagnostic thresholds published by various authors for the mean of daytime blood pressures obtained in men over 30 years old were between 88 and $94 \mathrm{~mm} \mathrm{Hg}$." With the device used in the present study the diagnostic threshold for a population of normotensive subjects varied from $91 \mathrm{~mm} \mathrm{Hg}$ for people aged below 40 to $94 \mathrm{~mm} \mathrm{Hg}$ for those aged 60 or more..$^{5}$ In a recent meta-analysis of 23 studies comprising more than 3000 subjects, Staessen et al estimated the diagnostic threshold at $91 \mathrm{~mm} \mathrm{Hg}$ for daytime measurement. ${ }^{21}$ Like these authors, however, we underline that the relevance of these limits in relation to cardiovascular morbidity and mortality has not been studied yet.

The two methods reached opposite conclusions on decision to treat in 31 of the 108 subjects. This group of patients had a mean blood pressure level inbetween those of the two other groups of patients in whom the 
treatment criteria were in agreement (see table II). This observation was true for measurement both by the physician and by the monitor. If the disagreement was due to a technical error we would expect the measurement error to be greatest in this group of patients. In fact, the measurement error in each group was related to the absolute blood pressure level, as expected from figure 1 . Another explanation could be an inappropriate choice of the treatment threshold. The arbitrary criterion based on reference values obtained in normotensive subjects, however, and the optimal threshold as determined by the receiver operating characteristic curve had comparable decisional value. The sensitivity and specificity of the former method were $61.4 \%$ and $78.1 \%$ respectively, figures not significantly different from those obtained by using the curve $(70.5 \%$ and $81.8 \%$ respectively). Consequently, it is unlikely that the classification obtained here would be altered by the use of a normality criterion derived from a larger sample of normotensive subjects. Classification errors reflect the random variation of blood pressures around the decisional threshold rather than an inappropriate choice of threshold or technical error in measurement.

We conclude that in a population of patients with mild hypertension a single 12 hour ambulatory blood pressure record selects the same proportion of patients to be treated as the WHO-ISH criteria.

Divergent conclusions, however, are often drawn at the individual level, which means that a single 12 hour ambulatory monitoring record cannot be proposed as a substitute for the WHO-ISH recommendations. The simultaneous use of the two methods in the same patient would result in confusion for both patients and physicians, as well as increased health care costs. In the absence of a prospective study comparing the incidence of cardiovascular complications in two groups of patients randomly allocated to one method or the other, a rational choice between these two methods for this type of patient is not possible. This problem is currently being researched by the home versus office monitoring (HOME) study.2 In the meantime the WHO-ISH recommendations remain a reasonable option which takes into account the results of major large scale multicentre controlled trials.

\section{Risk stratification for open heart surgery: trial of the Parsonnet system in a British hospital}

\section{Wythenshawe Hospital, Manchester M23 9LT Samer A M Nashef, senior registrar in cardiothoracic surgery Frances Carey, medical audit officer \\ Maureen M Silcock, medical audit coordinator P K Oommen, senior house officer in cardiothoracic surgery Richard D Levy, senior registrar in cardiology M T Jones, consultant cardiothoracic surgeon}

\section{Correspondence to:} Mr S A M Nashef, Papworth Hospital, Papworth Everard, Cambridge CB3 8RE.
We thank Pierre Corvol for his constant support throughout the study and Martin Day for editorial assistance. This work was supported by a grant from the Caisse Nationale d'Assurance Maladie des Travailleurs Salariès. 1. Mancia G, Parati G. Clinical significance of "white coat" hypertension.
Hypertchsiem 1990;16:624-6.

Management Committee of the Australian Therapeutic Trial on Mild Hypertension. Untreated mild hypertension. Lanct 1982;1:185-91.

3 Medical Research Council Working Party. MRC trial of treatment of mild hypertension: principal results. BMf 1985;291:97-104.

+ WHO/ISH. 1989 Guidelines for the treatment of mild hypertension. J Hypertens 1989;7:689-93

5 Pagny JY, Delva R, Aouizerate M, Chatellier G, Battaglia C, Devries C, et al. La pression arterielle ambulatoire des sujets normotendus. Presse Méd 1987:33:1621-4

6 Pagny J-Y, Chatellier G, Devriès C, Janod JP, Corvol P, Ménard J. Evaluation of the Spacelabs ambulatory blood pressure recorder: comparison with the Remler M2000. Cardiniascular Rev Rep 1987;7:31-6.

7 Bland JM, Altman DG. Statistical methods for assessing agreement between two methods of measurement. Lancet 1986;i:307-10.

8 Fleiss JL. Statistical methods for rates and proportions. New York: John Wiley, 1981.

9 Metz CE. Basic principles of ROC analysis. Siminars in Nuclear Medicine 1978;8:283-98.

10 Smith TDW, Clayton D. Individual variation between general practitioners in labelling of hypertension. BMI 1990;300:74-5.

11 Pickering TG, James GD, Boddie C, Harshfield GA, Blank S, Laragh JH How common is white coat hypertension? YAMA 1988;114:925-8.

12 Weber MA, Drayer JIM. Role of blood pressure monitoring in the diagnosis of hypertension. F Hypirtens 1987; 4(suppl 5):S325-S327.

13 Wacher B, Jacot Des Combes B. Porchet M. Biollaz J, Schaller MD. Brunner HR. Ambulatory blood pressure recording to identify patients who truly need therapy. 7 C/hrom Dis 1984;37:55-8.

14 Watson RDS, Lumb R, Young MA, Stallard TJ, Davies P, Littler WA. Variation in cuff blood pressure in untreated outpatients with mild hypertension--implications for initiating antihypertensive treatment. hypertension--implications

15 Conway J, Coats A. Value of ambulatory blood pressure monitoring in clinical pharmacology. $f$ Hypertens 1989;7(suppl 3):S29-S32.
p.

16 Casadei R, Parati G, Pomidossi G, Gropelli A, Trazzi S, Di Rienzo R, et al. 24-Hour blood pressure monitoring: evaluation of Spacelabs 5300 monitor by comparison with intraarterial blood pressure recording in ambulan patients. F Hypertens 1988:6:797-803

17 Burke MJ, Towers HM, O'Malley K, Fitzgerald DJ, O'Brien ET Sphygmomanometers in hospital and family practice: problems and recommendations. BMI 1982;285:469-71.

18 Bruce NG, Shaper AG, Walker M, Wannamethee G. Observer bias in blood pressure studies. F Hypertens 1988;6:375-80.

19 Armitage P, Fox W, Rose A, Tinker CM. The variability of measurements of casual blond pressure. II. Survey experience. Clin Sci 1966;30:337-44.

20 Pickering TG, Harshficld GA, Kleinert HD, Blank S, Laragh JH. Blood pressure during normal daily activities, slecp, and exercise. fAMA pressure during
1985:247:992-6.

21 Staessen Ja, Fagard RH, Lijnen IJJ, Thiis I, Van Hoof R, Amery AK. Mean and range of ambulatory blood pressure in normotensive subjects from meta-analysis of 23 studies. Am f Cardiol 1991;67:723-7.

22 Clement DL. Home versus office monitoring of blood pressure: a European multicentre study of high blood pressure. J Hypertens 1989;7(suppl 3) S49-S51.

(Accepted 28.August 1992)

\section{Patients, methods, and results}

All patients undergoing open heart surgery in the year from 1 March 1991 were studied. Risk data were obtained from the case notes by audit staff, who are not medically qualified. One of us (SAMN) was available to help locate or interpret data in case of difficulty. Predicted mortality was calculated and recorded preoperatively for every patient. Patients were classified into five risk groups: good (predicted mortality $0-4 \%$ ), fair $(5-9 \%)$, poor $(10-14 \%)$, high $(15-19 \%)$, and extremely high risk ( $20 \%$ or more). Operative mortality was defined as death temporally or causally related to surgery (death within 30 days of operation or in the same hospital admission as operation, regardless of cause). Information was entered into a database and results analysed by $\chi^{2}$ test for trend.

There was little difficulty in data collection. Audit staff spent an average of 10 minutes per patient in obtaining information from the case notes and less than five minutes per patient in entering data into the computer. Information was available unambiguously in $92 \%$ of patients and obtained with medical help in the remaining $8 \%$. Of 1071 patients studied, 202 were female $(19 \%)$, 97 were older than $70(9 \%), 317$ were hypertensive $(30 \%), 85$ were diabetic $(8 \%)$, and 17 were morbidly obese $(2 \%)$. Left ventricular function was good in $70 \%$, fair in $26 \%$, and poor in $4 \%$. Only 11 